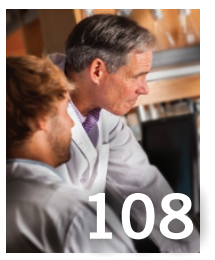

Diagnosis network:

Medical centers unite

to diagnose mystery

diseases

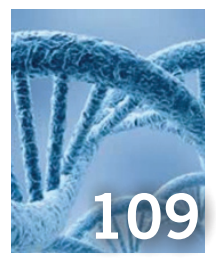

Silenced no more:

Big pharma firms

reembrace RNAi-based

therapeutics

\section{Council's course:}

The future of South

Africa's Medical

Research Council

\title{
Academic medical centers fear squeeze from Affordable Care Act
}

Teaching hospitals in the US have always juggled patient care and doctor training alongside their research missions. But the advent of the Affordable Care Act (ACA), which led to the creation of new insurance plans that became active on 1 January, is bringing changes to the financials of the country's academic medical centers (AMCs)and they may need to look for new revenue streams to sustain current funding levels for their research.

Profit margins from patient care have historically helped support research efforts at academic medical centers. Now, these US hospitals say the ACA is making the already contracting spending purse of AMCs shrink further-potentially threatening their ability to support research on the scale that they currently do.

"Research is an extremely important mission and requires a lot of investments, which puts extraordinary pressure on clinical operations, especially since clinical revenues and reimbursement are being reduced," says Michael Dowling, president of the Hofstra University-affiliated North Shore-LIJ Health System in Great Neck, New York.

Although AMCs receive considerable funding through the US National Institutes of Health (NIH), this money is generally subsidized by teaching institutions such as these. For example, for every dollar of external research funding that medical schools receive for benchtop studies, they generally supply an additional $26-40$ cents of support in the form of lab space, equipment, personnel and other expenses, according to a yet-unpublished survey of 40 medical schools conducted by the Washington, DC-based Association of Academic Health Centers (AAHC). "Most grants fall short, covering $60 \%$ to $75 \%$ of research costs, which is a long-standing trend," says AAHC President Steven Wartman. The revenue streams at medical schools must make up the difference.

The extent to which the ACA will affect teaching hospitals and their research differs largely by location. For example, 25 states, including Tennessee, have not yet opted to expand their federally funded Medicaid programs, thus choosing not to go ahead with a provision under the ACA that would give additional federal funding dollars to them to deliver health coverage to more low-income individuals and their families. Teaching hospitals in states that opted out of the Medicaid expansion might thus see even more uninsured patients than they already do. Plus, they might have to do so on a smaller budget, since the ACA eliminated a government subsidy for treating the uninsured. "AMCs are only about $5 \%$ of the nation's inpatient facilities but provide $40 \%$ of the country's uninsured care," says Jeff Balser, vice chancellor for health affairs and dean of the Vanderbilt University School of Medicine in Nashville, Tennessee. "Having nearly everyone insured would have helped us enormously in managing this significant expense."

\section{The long view}

Despite the concerns voiced at some teaching hospitals about tough financial times, Gerard Anderson believes the burden of providing health care for the uninsured from a lack of Medicaid expansion is probably temporary. Anderson, who is director of the Center for Hospital Finance and Management at the Johns Hopkins Bloomberg School of Public Health in Baltimore, anticipates that all states will opt in by 2016. According to Anderson, the ACA is, overall, a positive development for AMCs as there is now an influx of 10 million previously uninsured patients into the insured patient pool. "These institutions have been quite adaptive and will continue to innovate," he says.

Others emphasize that the hit from the ACA comes atop other financial pressures. An aging patient population is creating a larger pool of Medicare patients for which hospitals receive lower fees. A $2 \%$ cut to Medicare that was established by the US budget sequester in 2013 has made money tighter, as has the continued reduction in reimbursement from private insurance companies, according to AMC leaders. "The ACA is used as a metaphor for everything happening in health care, but really it's a piece" of the bigger financial picture, Vanderbilt's Balser says. Last year, Vanderbilt

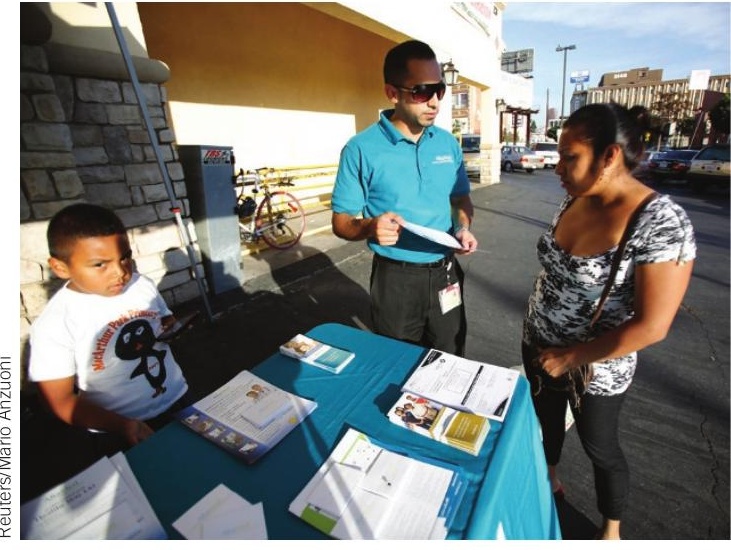

Side effects: Insurance sign-ups affect hospitals.

University Medical Center eliminated 750 open and unfilled positions and 500 people were let go, including research administrators and technicians (but no faculty).

Ultimately, the financial issues of each teaching hospital are as unique as are the solutions the institutions are beginning to test. Some of them have ramped up efforts to garner more philanthropic support, and others, such as North Shore-LIJ, have set up their own insurance companies to collect insurance premiums directly from the consumer as an income source.

Brigham and Women's Hospital in Boston is expanding its basic research through nongovernment partnerships with nearby life sciences companies, says hospital president Elizabeth Nabel, who sees her job as finding ways to expand the research funding pie. For example, Brigham and Women's and affiliated hospitals share a division called 'Partners Innovation' that coordinates its industry relationships and invests in startups based on technology developed at the two centers. The division also licenses their technologies, therapies, and diagnostics to capitalize on research and inventions.

"We need to continue to put pressure on the government to provide more funding," Nabel says. "But let's be realistic and creatively problem solve so our research programs don't suffer in the interim."

Anna Azvolinsky 